\section{Palofra}

acceso $\partial$ abierto

Cómo citar: Hernández, G., \& Espinosa, T. (2021). Prácticas eróticas de mujeres ñõñho de San Ildefonso, Amealco. Palobra, 21(1), 159-173. https://doi.org/10.32997/2346-2884vol.21-num.1-2021-3493

Recibido: 9 de febrero de 2021 .

Aprobado: 2 de junio de 2021.

Editor: Ricardo Chica Gelis. Universidad de Cartagena-Colombia.

Tipología IBN Publindex:

Artículo de Investigación Científica.

Copyright: @ 2021 . Hernández, G., \& Espinosa, T. Este es un artículo de acceso abierto, distribuido bajo los términos de la licencia https://creativecommons.org/licenses/by-

nc-sa/4.0/ la cual permite el uso sin restricciones, distribución y reproducción en cualquier medio, siempre y cuando que el original, el autor y la fuente sean acreditados.

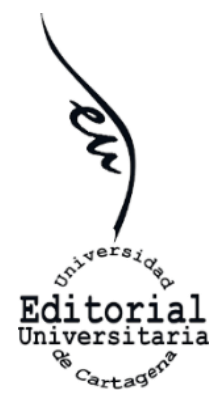

\title{
Prácticas eróticas de mujeres ñöñho de San Ildefonso, Amealco
}

\author{
Erotic practices of women ñöñho from San Ildefonso, Amealco
}

Guillermo Hernández González ${ }^{1}$

Universidad Autónoma de Querétaro-México, Guillermo.hernandez@uaq.edu.mx

Tamar Itzara Espinosa Ramírez ${ }^{2}$

Universidad Autónoma de Querétaro-México, itzaraer@gmail.com

\begin{abstract}
RESUMEN
El objetivo de este artículo es discutir los hallazgos de una investigación que explora los significados que mujeres jóvenes indígenas ñöñho (otomíes) atribuyen y construyen respecto a sus prácticas eróticas. Se realizó una investigación de campo en la comunidad San Ildefonso Tultepec en el municipio queretano de Amealco, a partir de una perspectiva instalada en la psicología cultural socioconstruccionista. El desarrollo de esta investigación etnográfica se dividió en dos fases: una diagnóstica y otra de profundización, se utilizaron como técnicas de investigación la entrevista semiestructurada, a profundidad y observación directa. La discusión central gira en torno a cómo las mujeres ñöñho de San Ildefonso construyen sus relaciones eróticoafectivas bajo la idea del amor romántico y reproducen sus fantasías y mitos.
\end{abstract}

Palabras clave: sexualidad femenina; prácticas eróticas; población indígena.

\begin{abstract}
The objective of this article is to discuss the findings of a research that explores the meanings that young indigenous ñöñho (Otomí) women attribute and construct with respect to their erotic practices. A field research was conducted in the community of San Ildefonso Tultepec in the Queretaro municipality of Amealco, from a perspective based on socioconstructionist cultural psychology. The development of this ethnographic research was divided into two phases: a diagnostic phase and an in-depth phase, using semi-structured and in-depth interviews and direct observation as research techniques. The central discussion revolves around how the ñönho women of San Ildefonso construct their erotic-affective relationships under the idea of romantic love and reproduce their fantasies and myths.
\end{abstract}

Keywords: female sexuality; erotic practices; indigenous population.

\footnotetext{
${ }^{1}$ Docente - investigador Universidad Autónoma de Querétaro.

${ }^{2}$ Psicóloga social Universidad Autónoma de Querétaro.
} 


\section{Introducción}

Amealco de Bonfil, se encuentra al sur de la capital de Querétaro, a $63 \mathrm{~km}$, de acuerdo con INEGI (2010), el 52\% de su población son mujeres y el $28 \%$ de las mujeres mayores de 12 años hablan una lengua indígena. De ellas, el 39\% no tienen educación básica, $56 \%$ concluyeron la educación básica y 5\% no está especificado (INEGI, 2010).

Encontramos que las mujeres ñöñho de Amealco son consideradas un foco rojo en términos de violencia: el gobernador del Estado en turno, Francisco Domínguez, aceptó que la violencia sufrida no es sólo física, también es psicológica, económica, patrimonial y sexual (Robledo, 2015), con lo cual podemos deducir que sus prácticas eróticas están inscritas dentro de este marco contextual. Respecto a la violencia sexual que viven las mujeres ñöñho se han realizado algunas investigaciones como "El abuso sexual y su relación con los suicidios de niñas, niños y adolescentes indígenas de Amealco" realizado por Cathia Huerta en 2012, que constó de talleres de diagnóstico para promover la salud sexual y tratar la violencia relacionada al abuso sexual, este estudio tiene como referente conceptual la perspectiva socioconstruccionista y las conclusiones son que:

los cambios acelerados en el contexto cultural de los Pueblos Indígenas y la impotencia de las comunidades ante la violación sistemática de sus derechos colectivos, propicia que la comunidad, como ente social, se autodestruya paulatinamente, originando en sus miembros efectos traumáticos (pág. 91).

En complementariedad, Araceli Colín (2009) nos dice que las niñas que sufren violaciones pierden a su padre y a su madre, las madres se hacen cómplices del agresor al silenciar y en algunos casos las segregan acusándolas de mentirosas, lo que suele desencadenar el suicidio. A pesar de que la investigación de Huerta da cuenta de algunas experiencias de abuso sexual, vemos que de manera institucional hay una tendencia a hablar de sexualidad indígena directamente relacionada con la violencia, al parecer hablar de género y de sexualidad, en específico en estos contextos, es hablar de relaciones de violencia.

La investigación interdisciplinaria de "Relaciones de género y sexualidad en indígenas otomís de educación secundaria” (2014), realizada por Claudia Osorio, Jorge Romero, Rubén Romero, Hilda Romero, reporta que el $62.8 \%$ de mujeres y el $65.9 \%$ de hombres afirmó que las mujeres deberían dedicarse a labores domésticas, el $81.4 \%$ de hombres y $80.5 \%$ de mujeres reconocieron violencia entre las parejas de novios adolescentes. El último dato nos interesa pues vemos que la violencia es un factor determinante que habla de la importancia de investigar la manera de significar las prácticas eróticas de las mujeres ñöñho, "Amealco de Bonfil es uno de los municipios del estado donde más se ejerce violencia contra la mujer, e incluso se considera como algo natural, por lo que niñas y niños replican actitudes aprendidas en el hogar" (Kaleydoscopio, 2015). Las relaciones de género, económicas, políticas y sobre todo culturales, organizadas jerárquicamente, basadas en el poder y la dominación, que 
construyen y que legitiman prácticas sociales en San Ildefonso como el incesto y el abuso sexual, son precisamente las que colocan a las mujeres ñöñho en una situación de vulnerabilidad desde niñas (Huerta, 2012).

El estudio de las relaciones de género en las comunidades indígenas es de gran importancia pues "bajo ese sistema, la consecuencia para las mujeres indígenas es su doble marginación y subordinación, una por ser mujeres y otra por ser indígenas. Esa discriminación se propicia tanto en el medio doméstico como en la sociedad en donde interactúan" (Sánchez, 2002). En general, "las comunidades otomíes se encuentran en un proceso de alta diversificación económica, política y religiosa en su interior, lo que se articula con la integración a los sistemas nacionales" (Questa \& Utrilla, 2006, pág. 53), estas comunidades han tenido que adaptar algunos elementos a su realidad social, resistir a otros y transformar su marco cultural: prácticas, lengua, creencias, por todo esto resulta muy importante comprender su contexto, actualización y miradas contemporáneas.

Basados en la psicología cultural se asume al ser humano como constructor su realidad, genera representaciones simbólicas, comparte significados con su comunidad social de manera que hombres y mujeres se comportan culturalmente (Aguirre, 2000).

Para Berger y Luckman (1980), el conjunto de significados y conocimientos compartidos entre muchas personas permite a los individuos generar interpretaciones de su realidad y transformarla o adoptarla (legitimación y conflicto, ahí es donde se construye conocimiento). De esta manera, la psicología cultural plantea que las subjetividades desarrolladas en un mismo contexto serán siempre similares porque comparten un mundo de significados. En cuanto a la visión ontológica del ser humano, ambas coinciden en que éste es un agente activo de su realidad que reproduce, interpreta, otorga y transforma significados (García-Borés J. , 2000).

Para la comprensión que buscamos, retomamos la vida cotidiana como "una realidad interpretada por los hombres [y mujeres] y que para ellos [y ellas] tiene el significado subjetivo de un mundo coherente" (Berger \& Luckman, 1980, pág. 36), así el pensamiento, las prácticas y las emociones tienen sentido en una realidad intersubjetiva que se comparte con el otro y que se da por establecida como realidad en una estructura de espacio-tiempo concreto. Los significados son aprehendidos en la interacción de la vida cotidiana, en la que nos vemos con el paso del tiempo más involucrados, por esto resulta significativo "conocer y explicar las experiencias intersubjetivas de los sujetos en sus entornos cotidianos" (Rizo, 2015, pág. 23).

Cada cultura otorga significados distintos a los fenómenos y procesos sociales, de modo que un mismo hecho es vivido de manera diferente en cada realidad específica, en tanto, "la cultura es un modo organizado y significativo de pensar la realidad” (Aguirre, 2000, pág. 135).

Por su parte, los estudios sobre la sexualidad en el siglo XIX surgieron como un ámbito de ciencias clínicas e individualistas como la psicología clínica, la 
psiquiatría, la pedagogía y la sexología y se ocuparon del funcionamiento "correcto" de la sexualidad de las personas bajo la idea de que ésta necesita control. Los discursos científicos sobre la sexualidad no son ajenos a su época y el discurso de las primeras ciencias que lo abordaron estuvo permeado por las religiones que lo antecedieron. Así, las diferentes disciplinas han mediado como ciencias verdaderas sobre las prácticas sexuales y reproductivas y liberaron de alguna manera a las personas respecto a las moralidades tradicionales al instalar una percepción 'natural' del impulso sexual (Szasz, 2004). El modelo biomédico fue el que instauró, principalmente, un patrón de conceptos como "degenerados, pervertidos y enfermos, que engloban desde el autoerotismo hasta los vínculos eróticos entre las mujeres" (Gómez, 2009, pág. 683), se construyó entonces el concepto de homosexualidad y se impuso la lógica que en gran medida guía la percepción de lo sexual hasta ahora.

Por el contrario, la perspectiva socioconstruccionista admite la sexualidad como una construcción social, es decir, que ésta contiene normas, comportamientos, estímulos y satisfactores socialmente apre(he)ndidos mediante un proceso de enculturación que nos permite otorgar significados y respuestas a lo sexual lejos del innatismo de una experiencia universal. Así, lo social delimitará el ejercicio de la sexualidad, las experiencias eróticas y la relación variable entre actos y significados sexuales. Rosío Córdova dice al respecto:

no sólo la variedad de comportamientos exhibidos por las distintas sociedades es grande, sino que el hecho de que cada grupo social defina sus propias normas en materia sexual y establezca fronteras entre lo que considera aceptable y lo reputado como "inadmisible" indica que fuera de unos pocos imperativos biológicos - el sexo es construido socialmente, sancionado socialmente y cargado de significaciones socialmente compartidas (2003, pág. 345).

Dolores Salinas (1996), aborda en la línea socioconstruccionista la sexualidad humana, asumiendo que las prácticas eróticas pueden ser significadas social y subjetivamente de forma distinta según su carácter histórico y cultural y nos propone nueve procesos graduales de sexualización cultural de las sociedades occidentales $^{3}$, de los cuales retomaremos tres que sirven para hablar de la construcción de significados de las prácticas eróticas por su origen socialmente construido:

- Categorización sexual: el sexo determinará socialmente lo esperado de cada sexo en las prácticas sexuales y dará identidad a dos géneros: masculino y femenino.

- Emocionalización de la interacción sexual: "emociones y significados a/en las interacciones, cuya característica fundamental es la participación de los órganos sexuales" (Salinas, 1996, pág. 243) que construyen relaciones afectivas y de poder.

\footnotetext{
${ }^{3}$ Los procesos de sexualización que propone Dolores Salinas son: 1) Categorización sexual, 2) Emocionalización de la interacción sexual, 3) Manipulación de la interacción sexual, 4) Erotización de la interacción sexual, 5) Progresiva aparición del fenómeno de la (hetero)sexualización de las emociones, 6) Funcionalización de la sexualidad, 7) Institucionalización de la heterosexualización, 8) Sexualización del individuo y 9) Erotización de la personalidad.
} 
- Funcionalización de la sexualidad: los fines y normas de las prácticas sexuales en sociedades tocadas culturalmente por el catolicismo: reproducción, monogamización y regulación de placer.

En los contextos sociales donde las mujeres tienen menor acceso a recursos, su pertenencia depende del estado de hijas o esposas, por eso se vuelve muy importante sostener la unión matrimonial; en este proceso los deseos personales de las mujeres pasan a segundo término, quedando primero la satisfacción de los varones. Al respecto, Ivonne Szasz dice: "los significados y las prácticas sexuales de las mujeres constituyen formas de adaptación y de resistencia a normas culturales, pero también representan estrategias relacionadas con las condiciones materiales de vida y con su situación social” (1998, pág. 81).

Al respecto, Ana María Fernández enfatiza en la importancia de considerar "la correlación dentro de una cultura entre los campos de saber que se inauguran al respecto, los tipos de normatividad que se establecen, las prácticas eróticas y amatorias que se visibilizan y las formas de subjetividad que se construyen" (2012, pág. 2).

Fernández (2012) nos dice que el dispositivo de la sexualidad moderna decreta, mediante saberes y ciencias, las relaciones y elecciones afectivo-eróticas, la moralidad y la estética de cada género: femenino y masculino. Entonces, cuando hablamos de prácticas eróticas nos referimos a aquellas en las que "el cuerpo [que tiene un papel principal] se muestra, se estiliza, desea e intenta ser deseado (...), prácticas de seducción, usos y disfrutes del cuerpo" (Bianciotti, 2011, pág. 70) que están sujetas a los criterios de normalidad, moralidad y disciplinamiento (Fernández, 2012) que determinan una forma de hacer- estar en el mundo como seres sexuados, y que según Bordieu, se ritualizan en el cuerpo en torno a las convenciones sociales.

En cuanto a la familia moderna y la religión, Esteinou (2004), a diferencia de Hipp (2006) o Flandrin (1979), dice que lo que en México conocemos como 'familia', no surgió desde la colonia sino a finales del siglo XIX y es, sobretodo, 'un entramado de relaciones socioculturales' y afirma que las modificaciones que en México surgieron respecto a la familia en la colonia fueron en parte por la conversión al catolicismo y sus preceptos, pero también las epidemias que redujeron a la población indígena y el debilitamiento de la reproducción cultural y étnica.

Por su parte, Roswitha Hipp (2006), hace un análisis acerca de cómo las instituciones de matrimonio y familia se fueron determinando según los fundamentos morales y sociales de la Iglesia y el Estado de manera que la institución matrimonial y familiar cristiana establece un orden social rígido, patriarcal y jerárquico soportado por estas dos instituciones. En una especie de punto de partida, Flandrin establece que tanto Iglesia, como la monarquía y el Estado, han establecido a lo largo de la historia el orden de las relaciones sociales basadas en el matrimonio y la familia; en las sociedades monárquicas, las relaciones de familia eran una institución pública y las formas de relación entre 
familiares eran modelo de las relaciones sociales, lo mismo era el rey a sus súbditos, como el padre a sus hijos, ambos sólo rendían cuentas a Dios (Flandrin, 1979). En este aspecto, concuerda Estrada (2008) en que la religión asegura la cohesión y legitima un cierto orden social, pero también hace hincapié en que, como parte la cultura, la religión permite aprehender significados y estructuras del medio en que nos desarrollamos, así, construimos valores y sentidos que se apoyan en instituciones.

La estructura familiar de los pueblos prehispánicos generalmente era patrilocal, esto quiere decir que se independizaban viviendo en su propia parcela las nuevas familias, sin embargo, no es una independencia total pues los vínculos con la familia de origen son muy fuertes. En las sociedades preindustriales, el matrimonio "era una cuestión de estrategia económica y política, pero también tenía algo que ver con las emociones. Claro que esta aseveración es más válida en estamentos altos de la sociedad" (Hipp, 2006, pág. 61).

En el modelo de familia moderno, se espera que la familia nuclear vaya a vivir a una vivienda distinta a la de sus padres, los integrantes de la familia estarán determinados económicamente según sus actividades laborales y éstos estarán relacionados afectivamente no sólo por la parentela aunque muchos estudios han mostrado "la disfuncionalidad y la incapacidad de la familia nuclear "aislada" de afrontar el contexto urbano-industrial y la importancia, en este sentido, de las relaciones de parentela" (Esteinou, 2004, pág. 104). En complementariedad, Hipp (2006) afirma que "la concepción de la familia tiene mucho que ver con el modelo matrimonial, influenciado desde siempre por la Iglesia católica y reafirmada por el Estado, basándose en un modelo monogámico y patriarcal que rechaza y persigue los comportamientos sexuales que se apartan del orden social establecido" (2006, pág. 76), en zonas rurales del siglo XIX las familias además estuvieron atravesadas por condiciones económicas y laborales precarias, por lo que era muy importante cuidar el orden familiar con el fin de lograr una unidad que asegurara el trabajo y la producción.

Con lo anterior, Rosario Esteinou asevera que prevalecen las concepciones comunitarias aunque la familia nuclear en México se vuelve un espacio de intimidad, sexualidad y afectividad, aunque no por excelencia, porque también lo es del respeto y la obediencia por lo que la patrilocalidad, por ejemplo, siguió estableciendo fuertes vínculos en las familias y la comunidad, nos dice "las tendencias fuertemente endogámicas reforzaban, asimismo, sus pautas culturales tradicionales, la cohesión étnica y familiar y se erigían como una barrera que impidió la profunda penetración de las pautas individualizantes" (2004, pág. 133). De aquí la gran importancia de comprender las funciones y los significados que permiten las religiones en las sociedades como parte de las culturas, entendiendo que "la religión es una creación humana que está relacionada con experiencias antropológicas fundamentales. Por un lado, está la toma de conciencia del significado del nacimiento y de la muerte, es decir, de la contingencia y finitud del hombre, y de la inseguridad y angustia que conlleva" (Estrada, 2008, pág. 111). La religión otorga respuestas acerca del sufrimiento, del origen, en fin, del sentido de la vida y, a partir de este, todos nuestros autores concuerdan con que ésta (la religión) plantea un orden social y valores, 
motivaciones y prohibiciones, conocimientos, creencias y pautas y dinámicas de comportamiento, es decir, "protege y vive de la moral, con la que interacciona, pero ni se reduce a ella (ya que es, sobre todo, una instancia de sentido) ni la moral depende de la religión" (Estrada, 2008, pág. 112).

En San Ildefonso Tultepec radican mayoritariamente personas ñöñho, las formas de organización comunitaria, familiar y su identidad, son aspectos importantes para la comprensión del contexto al que nos referimos. Según Prieto y Utrilla (2006) los mengú, que son las personas que viven en la misma casa, reconocen al ar ta (el padre de mayor edad) como jefe de la familia, que está constituida por padre, madre e hijos varones solteros y casados y sus respectivas esposas e hijos. Para las comunidades ñöñho, el matrimonio es la responsabilidad que adquieren de formar una familia y es a partir del nacimiento del primer hijo que son considerados 'adultos'. Diego Prieto y Beatriz Utrilla (2006) concuerdan con que esta comunidad se organiza a partir del grupo doméstico, entonces el matrimonio se realiza generalmente de manera endogámica y el hijo varón es quien hereda del jefe de familia para construir su propia casa, es la mujer quien irá a co-habitar la casa del varón y en caso de fallecer éste, ella no la hereda sino que se reparte entre los otros hijos del jefe de familia, en caso de que no haya, puede heredarla siempre y cuando la trabaje y no vuelva a casarse. Sin embargo, "la creación un grupo doméstico requiere de cierto periodo de convivencia (bajo la mirada de los padres) después del matrimonio" (Questa \& Utrilla, 2006, pág. 21).

Respecto a la construcción de roles el “'ser “joven” y el matrimonio en San Ildefonso, Amealco, significa asumir roles y funciones culturalmente determinados que generalmente se traducen en responsabilidades" (Huerta, 2012, pág. 29). Fabiana Sánchez nos dice las funciones y saberes son transmitidas generacionalmente, son las y los ancianos los que se encargan de extender conocimientos, habilidades y actitudes, "en el caso actual de la mujer otomí, adulta y anciana (...), les fueron transmitidos a su vez por sus antecesoras que, en su madurez y vejez, heredaron su saber, su hacer y su deber ser de mujeres. (...) El objetivo de las mujeres, ancianas y adultas, es transmitir su saber a sus congéneres para dar continuidad a los elementos identitarios de género" (2002, pág. 206). En concordancia, Alessandro Questa y Beatriz Utrilla (2006) nos dicen que la organización familiar en las comunidades ñöñho se ve reflejada en la construcción de sus casas, donde se desarrollan sus vidas. La cocina y el fogón son lugares muy importantes para las mujeres, ahí las abuelas y niñas comparten gran parte del día, "es en la cocina donde se calienta el cuerpo, se muele el maíz, se prepara la comida y se habla de los saberes diarios; también es ahí donde existe el espacio privilegiado de 'la costumbre”" (2006, pág. 18).

Aunque esto persiste, debido a la migración de varones, las mujeres han tenido que asumir la jefatura del hogar y muchas han sido abandonadas, madres solteras o viudas, así, ellas cada vez más forman parte de otras actividades como la siembra y organización de fiestas y celebraciones, sumado al cuidado de sus hijos, hogares y pastoreo. La migración es un fenómeno constante en las comunidades indígenas hoy día, las mujeres migran en menor cantidad que los varones debido a las necesidades de las comunidades. Diego Prieto y Beatriz Utrilla hablando de mujeres indígenas, nos dicen que "debido a la migración, 
muchas de las dinámicas de las unidades domésticas han tenido que cambiar, recayendo sobre las mujeres recientes responsabilidades" (2006, pág. 83). En este sentido, Dalia Cortés afirma que hay cambios también en cuanto a la educación en las comunidades 'hñahñu' (sic.), donde "las mujeres jóvenes que estudian niveles medios superiores (bachiller, universidad y carreras técnicas) retrasan su unión en pareja y la maternidad" (2014, pág. 399), sin embargo persiste un control patriarcal que busca cuidar y mantener el honor de las familias a través de la buena reputación de las hijas. Respecto a este honor, en las comunidades 'hñahñu' (sic.), "las mujeres que rompen con el rol tradicional, tratando no solamente de construir una vida más independiente del núcleo familiar, sino también haciendo escuchar su voz en espacios públicos, son penalizadas por las normas de la comunidad" (Cortés, 2014, pág. 402).

A partir de lo anterior resulta importante indagar sobre la manera en que las mujeres de San Idelfonso significan el erotismo, por lo que el objetivo del presente artículo es comprender cómo significan las mujeres ñöñho de 20 a 25 años de esta comunidad.

\section{Metodología}

La investigación se llevó a cabo en dos fases: a) la primera de diagnóstico, en la que se tuvo como objetivo identificar en el discurso y en las prácticas en el espacio público, las prácticas eróticas de las mujeres jóvenes ñöñho y, b) la segunda tuvo por objetivo identificar los significados atribuidos a las prácticas eróticas detectadas.

En ambas fases asumimos que la complejidad de la realidad estudiada no puede ser aprehendida en su totalidad y, al contrario, es una relación inseparable de elementos independientes de nuestras prácticas que se vuelven sensibles al acercarnos, igualmente son susceptibles de ser significadas. La interpretación entonces dependerá de la construcción que se haga en relación con la teoría, misma que no es un sistema estático, sino abierto, en el que la realidad moldea a la teoría; asumirla así permite la participación activa de la investigadora aceptando que las tensiones de ese momento particular permiten sólo ese desarrollo del modelo.

Siendo parte de la metodología cualitativa, utilizamos el método etnográfico (Guber, 2004) porque concebimos el conocimiento como una construcción comprensiva que permite enunciar fenómenos observables (prácticas, nociones, conductas y representaciones) de un mundo concreto y las significaciones que le otorgan las actoras desde una mirada histórica y cultural. Como lo menciona Aldo Ameigeiras, la investigación etnográfica (en su concepción semiótica de la cultura) sirve ante la "necesidad de comprensión de los otros y de conocimiento de una diversidad cultural, que comienza a descubrirse en su multiplicidad y sus diversas formas de relación y contacto" (Ameigeiras, 2006).

En la primera fase, se realizaron 3 entrevistas semiestructuradas a mujeres jóvenes ñöñho de entre 23 y 25 años. Las tres tienen de 1 a 2 hijos, dos de ellas vivieron con su pareja de 1 a 2 años y ahora no viven con ellos, una de ellas 
nunca vivió con quien fue su pareja, dos de ellas son católicas y una no profesa ninguna religión y su escolaridad es distinta (primaria, bachillerato y licenciatura). Las entrevistas fueron grabadas en audio y luego transcritas. La entrevista cualitativa fue utilizada porque da a las informantes posibilidades de libertad de expresión y profundidad de ideas, sentimientos y puntos de vista lo suficientemente flexibles a su disposición de compartir, las preguntas son abiertas y por lo tanto las respuestas, en concordancia, posibilitan la indagación acompañada por un marco de realización empático (Martínez, 2011, pág. 38).

La observación directa se realizó en 6 visitas a la comunidad entre septiembre y octubre del año 2016, permitió la producción de información sin dirigirse inmediatamente a las actoras, registrando a partir de algunos indicadores los comportamientos a observar, esto fue registrado en un cuaderno de notas y un diario de campo (Martínez, 2011, pág. 34). La observación directa se llevó a cabo en dos espacios públicos: la plaza y la Iglesia, donde se observaron las relaciones entre hombres y mujeres, y el discurso acerca de sus prácticas eróticas.

En la segunda etapa se realizaron 3 entrevistas a profundidad porque esta técnica permite el diálogo en una acción no directiva ni impositiva, de manera que se convierte en una herramienta de encuentro con la otra en el que podemos profundizar en la comprensión de significados y experiencias psicológicas de las entrevistadas, valorando la diferencia y reconociendo la igualdad en una relación recíproca de sujetos capaces de sentir y pensar (Ameigeiras, 2006). Con base en las entrevistas semiestructuradas realizadas anteriormente, las entrevistas a profundidad siguientes, fueron enfocadas en el sentir y pensar de las mujeres ñöñho, así como en las funciones asignadas a sus prácticas eróticas.

\section{Resultados}

Hemos encontrado que las mujeres ñöñho construyen sus relaciones eróticoafectivas en torno a la idea occidental del amor romántico, dos elementos sostienen en la comunidad esta idea: la familia moderna y la religión subjetivan a las mujeres, de manera que ellas reproducen las fantasías y mitos del amor romántico.

Existe un "acceso brutal" a los cuerpos de las mujeres ñöñho en relación al control de la reproducción y el terror sistemático del pecado, el cristianismo se ha encargado de subjetivar a la comunidad con la idea del bien y el mal, las que marcan el ejercicio de su sexualidad. Así, los instintos sexuales deben ser sublimados y dirigidos sólo hacia la reproducción, lo que legitima la idea de que el romance sólo se vive fuera del matrimonio, por lo que las prácticas de cortejo se viven sólo en el noviazgo y las relaciones extramatrimoniales.

El acceso a los cuerpos además puede verse en la tarea femenina de complacer a su pareja, la asunción de que las mujeres son las encargadas de sostener afectivamente las relaciones amorosas y que éstas deben ser bellas para ser amadas, por lo que las mujeres entrevistadas refieren buscar estar lo más arregladas posibles para sus cortejantes. 
Por el lugar geográfico en el que se encuentran estas mujeres ñöñho, la televisión ha sido un elemento occidentalizante que a nivel intersubjetivo incide en su construcción de "mujer bonita", tomando algunos elementos del estereotipo que ahí se reproduce: delgada, maquillada, usa tacones, comprendemos entonces que la preocupación por su aspecto físico comience a partir del interés de/por un hombre y ya no quieren verse como niñas, comienzan a adornarse el cabello, maquillarse y usar zapatos de tacón pequeño, como parte de una cultura en la que las mujeres visten con faldas hasta los tobillos, en la misma intersubjetividad existen pautas morales que sancionan a las mujeres que muestran los muslos con faldas arriba de las rodillas.

En el cortejo, las mujeres jóvenes se pasean solas o en grupo por la avenida principal para que el hombre que les gusta las vea, se bañan, se visten con la ropa que más les gusta o con el traje típico que les resulta "muy elegante". Los hombres jóvenes se ayudan de otro para cortejar a la joven que le gusta, se ayudan al entregar regalos o recados, estas pautas de comportamiento están relacionadas con su representación de la realidad, en la que el "tratarse bien" es descrito por ellas como respeto, no decirse groserías, no golpes y apoyarse, y asumen como parte de los roles de género el que los hombres tengan como responsabilidad "dar el gasto" y como suyas, el tener relaciones sexuales, ser cariñosas y atender la casa y a sus hijas e hijos.

Para que las mujeres jóvenes ñöñho construyan relaciones afectivas con los hombres que les muestran interés, es muy importante para ellas que ellos les "hablen bonito", les digan que las quieren o que están enamorados. Cuando una pareja inicia el noviazgo, las muestras de amor esperadas de ambos son besos "con amor", lo que hace que ellas se sientan "como parte de esa persona". Los abrazos son sentidos como un acto de protección, les brinda seguridad, aunque estas muestras de amor no son iguales en el espacio público que en el privado, en el primero deben ser mucho más reservadas para no ser estigmatizadas como "locas" o mujeres "que no se respetan".

Acerca del concepto de amor, una de las mujeres entrevistadas decía "sentimos que el querer es amor (...), y a la mejor yo ni lo quiero, pero él ya me dijo que me quiere, ¡ah bueno!, entonces, pues sí, sí me voy con él”. Nos dice que la falta de muestras de cariño por parte de los padres, cosa culturalmente sancionada, provoca que las mujeres se sientan atraídas ante las primeras muestras de interés, estas pautas de comportamiento que encontramos, dan cuenta de las relaciones que construyen hombres y mujeres ñöñho. Dos de las entrevistadas concuerdan en que, luego de juntarse, comienzan a desaparecer las muestras de amor que sí había en el noviazgo o se vuelven prácticas menos cotidianas, lo que nos muestra cómo las prácticas legitimadas en las etapas de la relación de pareja son diferentes para actores sociales específicos en situaciones distintas, por ejemplo, en una separación a quien preguntan la razón es inmediatamente a la mujer, con la sospecha de que ellas hicieron mal algo, esto da cuenta de las responsabilidades que se les encargan, institucionalizando los roles de género.

Las mujeres en su primera relación sexual por lo general están enamoradas, no es algo planeado, más bien es algo "que se da" y en el que se sienten cómodas, 
contentas y nerviosas. Sin embargo, hay también quienes son presionadas para hacerlo y es en razón de una muestra de amor por lo que acceden, aunque no se sientan preparadas, si es así, el hombre decide cuándo se inician. Como parte de la cultura católica que les prohíbe usar anticonceptivos, no los utilizan, pero después se preocupan por un posible embarazo, la mayoría se embaraza iniciando su vida sexual y dependerá de las decisiones de pareja el seguir teniendo relaciones; quienes utilizan condón es por iniciativa y preocupación del varón.

Además, relacionado con el contexto católico, las mujeres sólo tienen permitido tener relaciones sexuales con un hombre, lo que se vuelve importante para ellas por mantener la tradición y por la creencia religiosa que lo impone. Aun así, la infidelidad resulta algo normal en la comunidad, si la infidelidad no provoca problemas o separación entre parejas, no hay mayor problema en la comunidad, pero sí si "le quitas el hombre a alguien". Las mujeres que muestran mucho su piel con ropa corta y mujeres con preferencias sexuales no heteronormativas son estigmatizadas en la comunidad como "putas".

Encontramos que una de las funciones de tener relaciones sexuales es la procreación, otra es la monogamización de las relaciones afectivas, como ellas lo mencionan: para demostrar amor a sus parejas, y por último la pertenencia: "para no ser como rechazadas o pertenecer dentro de alguien".

En cuanto al papel de las mujeres en las relaciones sexuales, encontramos que hay prácticas legitimadas para ellas que dan origen a dos estereotipos de mujeres: las reservadas y "las otras". Las primeras tienen relaciones sexuales por amor y por complacer a su pareja, las otras, que consumen alcohol y drogas, se relacionan con más de un hombre en el encuentro sexual y lo hacen "por gusto", bajo esta idea, existe el miedo de que los hombres duden de ellas si "tocan mucho", paradójicamente, si no participan en las relaciones sexuales con besos y caricias, las colocan como "frías". Emborracharse es una práctica no sancionada para los hombres, por el contrario, ellos tienen permitido socialmente hacerlo en exceso mientras cumplan con sus responsabilidades económicas y laborales, incluso llegan a gastar el dinero de lo que su pareja produce, las mujeres que lo hacen y que conviven con varones son mal vistas. De una u otra manera, se reproduce la idea de que las mujeres son para que los hombres satisfagan "sus necesidades" sexuales, y ellas lo asumen.

Como parte del alto valor que se le da a la monogamización, las mujeres se alientan para "seguir aguantando" infidelidades y violencia por parte de sus parejas incluso desde el noviazgo, por el contrario, tanto hombres como mujeres legitiman que ellos "anden con una y con otra". Vemos que cuando una mujer no se comporta sumisa el reclamo de la comunidad es que "tú ya incluso le estás faltando a la cultura, o sea ya no eres, estás rompiendo con tradiciones de la comunidad", lo que nos habla de la manera en que la cultura es constitutiva de características de sus actores sociales. Esto es mucho más común en mujeres de 30 años para arriba, "la gente joven ya se les hace raro ver esas situaciones", aunque mencionan que es difícil salir de eso en una comunidad machista.

En el proceso diagnóstico pudimos identificar que en la etapa de noviazgo de las mujeres ñöñho es común que el trato con el novio sea cordial y afectuoso, sin 
embargo, la siguiente etapa será en la que co-habiten con su pareja y estas prácticas eróticas perderán espontaneidad. Aun así, es muy importante para ellas que los hombres interesados en tener una relación, les "hablen bonito", además de la sensación de seguridad que les proporcionen con gestos como besos y abrazos.

Tradiciones y creencias propias del catolicismo y la cultura ñöñho no permiten que las mujeres tengan muchas posibilidades de libertad de decisión en cuanto a su cuerpo y su sexualidad, asumen la idea de relacionarse sexualmente sólo con un hombre, de vestirse de manera que sólo muestren cara, brazos, manos, pies y pantorrillas, también existen estereotipos que guían algunas de sus prácticas como el arreglo personal y la preocupación por su apariencia física.

Vemos que el juntarse o casarse con un hombre de la comunidad, es signo de prestigio, esto potencia que una mujer permita que su pareja varón sea violento o no aporte económicamente, además da cuenta de la violencia que ejercen las mujeres hacia otras mujeres: éstas suelen desprestigiar, incluso golpear a otra ante la comunidad cuando es sospechosa de ser amante de algún hombre.

Las mujeres son castigadas socialmente por otras mujeres cuando su comportamiento no es sumiso y reservado, ellas se encargan de vigilar y sancionar las prácticas eróticas de otras mujeres cuando éstas no son valoradas como buenas o aceptables. Es común que se etiqueten entre ellas y se alienten a continuar las "tradiciones" de la comunidad.

\section{Conclusiones}

Tras las entrevistas y las observaciones etnográficas se puede observar una gran influencia de la sexualidad occidental y sus instituciones de sanción en la conformación subjetiva de las mujeres ñöñho, sobre todo en el lugar de sumisión y aceptación del deseo masculino en las prácticas eróticas, siendo normalizadas formas de violencia o bien el cambio en la forma de relacionarse a partir de la cohabitación, además de prácticas de asimilación del erotismo occidental desde las coordenadas de su sistema cultural, por ejemplo, usar tacón pero sólo el permitido por la comunidad.

Queremos enfatizar el sistema de vigilancia que se encuentra dentro del sistema relacional entre mujeres, pues son ellas las encargadas de mantener el disciplinamiento en torno al erotismo; pues las sanciones, que se asignan a una mujer que no cumple con las prácticas socialmente aceptadas, son generalmente ejercidas por las otras mujeres de la comunidad.

El amor romántico, como modelo relacional, resulta fundamental al entender las significaciones del erotismo en la población entrevistada, en concordancia con los estudios sobre amor en occidente encontramos que el ideal del amor romántico subjetiva a las mujeres ñöñho, así, ellas se subordinan ante sus parejas idealizándolos e idealizando su relación, construyen una fantasía acerca del futuro con esa persona que eleva sus expectativas, (Esteban \& Távora, 2008), las cuales no corresponden con la experiencia, dando lugar a relaciones desiguales 
puesto que los hombres son construidos subjetivamente para que el enamoramiento termine, lo que los coloca en un lugar de supremacía y privilegio en las relaciones amorosas mientras que las mujeres somos construidas subjetivamente para dar, buscamos el beneficio y cuidado del otro para que nos amen (Lagarde, 2001). Las mujeres se asumen como las encargadas del cuidado del amor del hombre, lo que en la comunidad es altamente valorado, esto deviene en una necesidad de ser querida (llenando carencias afectivas) y la angustia por no serlo, además de reforzar el papel del hombre como proveedor económico (y ellas de afecto) (Esteban \& Távora, 2008).

Desde lo hallado se encuentra pertinente ahondar en los estudios sobre el erotismo femenino en comunidades originarias desde la voz de las mujeres, con la intención de alejarnos de los estereotipos de mujeres indígenas víctimas y dar cabida al significado inter-subjetivo que las mujeres ñöñho construyen de sus prácticas eróticas en su contexto como agentes que perpetúan las prácticas de su cultura, con lo que se requiere una investigación que humanice a las actoras sociales con quienes trabajamos, que les devuelva agencia y voz desde sus contextos, apostamos por una investigación comprensiva que pueda ser precedente de futuras (de)construcciones.

De esta manera, resulta importante el estudio de las relaciones de género de las comunidades indígenas en nuestro país pues ellas han vivido un proceso, poco estudiado en este ámbito, de adaptación-resistencia en la tensión entre lo tradicional y lo moderno que ha transformado su realidad social y la de México.

\section{Referencias Bibliográficas}

Aguirre, Á. (2000). Demarcación de la psicología cultural. Anuario de psicología, 109-137.

Ameigeiras, A. (2006). El abordaje etnográfico en la investigación social. En I. Vasilachis, Estrategias de investigación cualitativa (págs. 10-151). Barcelona: Gedisa editorial.

Berger, P., \& Luckman, T. (1980). La construcción social de la realidad. Buenos Aires: Amorrortu.

Bianciotti, M. C. (2011). Cuerpo y género: apuntes para pensar prácticas eróticas de mujeres jóvenes. Aportes de Judith Butler y Pierre Bourdieu. Revista Latinoamericana de Estudios sobre Cuerpos, Emociones y Sociedad, 70-82. Obtenido de http://www.relaces.com.ar/index.php/relaces/article/viewArticle/83

Colín, A. (2009). Abuso sexual incestuoso a niñas indígenas de Querétaro, México. Una mirada psicoanalítica. II Congreso Internacional de investigación en psicoanálisis, derecho y ciencias sociales. Santiago del Estero.

Córdova, R. (abril-junio de 2003). Reflexiones teórico-metodológicas en torno al estidos de la sexualidad. Revista Mexicana de Sociología(2), 339-360. 
Cortés, D. (2014). Las jóvenes hñahñu en contextos de migración. En M. Pérez, \& L. Valladares, Juventudes indígenas. De hip hop y protesta social en América Latina (págs. 385-416). México: INAH.

Esteban, M.-L., \& Távora, A. (2008). El amor romántico y la subordinación social de las mujeres: revisiones y propuestas. Anuario de psicología, 59-73.

Esteinou, R. (julio-diciembre de 2004). El surgimiento de la familia nuclear en México. EHN 31, 99-136.

Estrada, J. (2008). Antropología, cultura y religión. Convivium 21, 99-120.

Fernández, A. M. (2012). El orden sexual moderno y las diversidades sexuales. Revista Actualidad Psicológica(411).

Flandrin, J.-L. (1979). Introducción. En J.-L. Flandrin, Orígenes de la familia moderna (págs. 1-7). Barcelona: Crítica. Obtenido de http://www.iin.oea.org/Cursos_a_distancia/origenes_de_la_familia_moderna.pdf

García-Borés, J. (2000). Paisajes de la psicología cultural. Anuario de Psicología, 925.

Gómez, Á. (2009). El sistema sexo/género y la etnicidad: sexualidades digitales y analógicas. Revista Mexicana de Sociología, 675-713.

Guber, R. (2004). El salvaje metropolitano. Recnstrucción del conocimiento social en el trabajo de campo. Buenos Aires: Paidós.

Hipp, R. (2006). Orígenes del matrimonio y de la familia modernos. Revista Austral de Ciencias Sociales, 59-78.

Huerta, C. (2012). El abuso sexual y su relación con los suicidios de niñas, niños y adolescentes indígenas. Santiago de Querétaro.

Illouz, E. (2009). La construcción de la utopía romántica. En E. Illouz, El consumo de la utopía romántica: el amor y las contradicciones culturales del capitalismo (págs. 49-79). Buenos Aires: Katz Editores.

INEGI. (2010). Censo de población y vivienda 2010. Obtenido de http://www.inegi.org.mx/lib/olap/consulta/general_ver4/MDXQueryDatos.asp?\# Regreso\&c $=27954$

Kaleydoscopio. (17 de mayo de 2015). NTR periodismo crítico. Obtenido de http://ntrzacatecas.com/2015/05/17/amealco-mujeres-atrapadas-entre-violenciay-pobreza/

Lagarde, M. (2001). Para deconstruir el amor como subordinación y dominio. En M. Lagarde, Claves feministas para la negociación en el amor (págs. 67-84). Distrito Federal: Puntos de encuentro. 
Lugones, M. (2011). Hacia un feminismo descolonial. La manzana de la discordia, 105-117.

Martínez, J. (2011). Métodos de investigación cualitativa. Silogismos. Más que conceptos.

Molina, Y. (2010). Teoría de género. Contibuciones a las Ciencias Sociales. Obtenido de http://www.eumed.net/rev/cccss/10/ymb2.htm

Osorio, C., Romero, J., Romero, R., \& Romero, H. (2014). Relaciones de género y sexualidad en indígenas otomís de educación secundaria. DigitalCiencia@UAQro. Obtenido de http://www.uaq.mx/investigacion/revista_ciencia@uaq/ArchivosPDF/v8n1/6.pdf

Pizzinato, A. (2010). Psicología cultural. Contribuciones teóricas y fundamentos epistemológicos de las aportaciones de Vygotsky hacia la discusión lingüística de Bakhtin. Univ. Psychol., 255-261.

Prieto, D., \& Utrilla, B. (2006). Ya hnini ya jä'itho Maxei. Los pueblos indios de Querétaro. México: CDI.

Questa, A., \& Utrilla, B. (2006). Otomíes del norte del Estado de México y sur de Querétaro. Estado de México: CDI.

Rizo, M. (2015). Construcción de la realidad, cominucación y vida cotidiana. Una aproximación a la obra de Thomas luckmann. Intercom, 19-38.

Robledo, L. (22 de diciembre de 2015). Alerta en Amealco por violencia de género. El universal. Obtenido de http://www.eluniversalqueretaro.mx/politica/22-122015/alertan-en-amealco-por-violencia-de-genero

Salinas, D. (1996). La construcción social de la identidad sexual de la mujer, un análisis multirepresentativo.

Sánchez, F. (2002). Género y saberes otomíes: relación mediada por la lengua. El caso de Pueblo Nuevo, municipio de Acambay, Estado de México. Estudios de cultura otopame (págs. 201-220). D.F: UNAM.

Szasz, I. (1998). Sexualidad y género: algunas experiencias de investigación en México. 77-104. Obtenido de http://equidad.org.mx/ddeser/seminario/internas/lecturas/lectsexual/sexualidadygenro.pdf

Szasz, I. (2004). El discurso de las ciencias sociales sobre las sexualidades. En C. Cáceres, Ciudadanía sexual en América Latina: abriendo debate (págs. 65-75). Lima: Universidad Peruana Cayetano Heredia. 